\title{
Pilot single-centre cross-sectional study to determine emergency physicians' knowledge and management of sports concussion: an experience from Singapore
}

\author{
Dinesh $\underline{\text { Sirisena }}^{1,2}$, FFSEM(Ire), FFSEM(UK\&l), Joy $\underline{\text { Walter }}^{3}$, MSc, Grad Dip Phys, Joo Haw Ong $^{1}$, MBBS, FAMS,
} Joanne Probert $^{1,2,4}$, MFSEM(UK), FCEM(UK)

\begin{abstract}
INTRODUCTION Sports concussion remains challenging to manage despite changes to policy and practice since the 2012 International Consensus Conference on Concussion in Sport. Emergency physicians (EPs) are usually the first line of medical care for athletes in amateur and youth collision sports. This single-centre cross-sectional study aimed to establish EPs' understanding and management of concussion in Singapore.

METHODS An anonymised, 17-item online questionnaire was sent to EPs requesting for information on their clinical experience, training, exposure to concussion cases in the emergency department (ED) and assessed knowledge of the condition.

RESULTS Out of 65 EPs, 52 (80\%) responded, 25 (48.1\%) of whom were medical officers. Over 90\% had not received formal training in concussion management, and $73.1 \%$ regularly assessed concussion. 40 (76.9\%) EPs recognised that loss of consciousness was not essential for diagnosis and only 24 (46.2\%) knew the most common symptom. 26 (50.0\%) incorrectly reported that they would perform brain imaging. Among those who indicated onward referral, 29 (55.8\%) would refer concussed patients to neurosurgery. There were no significant differences between clinical grade or training in concussion and positive responses for definition, imaging modality or most common symptom of concussion.

CONCLUSION Concussion is a common presentation to EDs in Singapore. However, understanding of the condition, its clinical diagnosis, investigation and onward management is limited. Although EPs reported training in concussion, it is likely to be insufficient. Commencing relevant education programmes for undergraduate and postgraduate medical students may enable progressive acquisition of knowledge and thereby improve patient management in the future.
\end{abstract}

Keywords: clinical pathways, education (medical), emergency department, emergency medicine, sports concussion

\section{INTRODUCTION}

Since the 2012 International Consensus Conference on Concussion in Sport held in Zurich and its subsequent consensus statement, ${ }^{(1)}$ concussion has remained a hot topic in Sports and Exercise Medicine (SEM), kept in the headlines by on-and-off field events and considerable media interest in the subject. ${ }^{(2)}$ A well-known example is the American National Football League lawsuit, ${ }^{(3)}$ where former players successfully brought claims against the sport's governing body for not being transparent about the long-term consequences of concussion and for its poor overall management of the condition. ${ }^{(4)}$ In response to this, there have been calls from health professionals to ban contact in youth sports, only to be countered by experts in SEM, who claimed that adopting such an approach was not the solution. ${ }^{(5)}$

With this constant attention, a number of policy changes, advancements in technology and awareness programmes focusing on concussion have been established. ${ }^{(6)}$ Numerous authors have also challenged the knowledge of the management of concussion among stakeholders such as coaching staff,(7,8) athletes $^{(9,10)}$ and families $^{(11)}$ of youth players. However, recent systematic and qualitative reviews of educational initiatives targeting athletes have suggested that these efforts are of limited benefit. ${ }^{(12,13)}$
While we could argue that these educational initiatives remain important in our attempt to improve outcomes, we should also be challenging clinical management by clinicians. In particular, pathways emanating from the emergency departments (EDs) must be assessed, since concussion is a common presentation. ${ }^{(14,15)}$ This is even more important when a patient presents to the ED after sustaining a head injury at a sporting event where no medical professionals trained in immediate care and concussion management are available on site. Therefore, the emergency physician (EP) represents the first line of clinical management for concussions. Since this is more likely to be the case for youth athletes ${ }^{(16,17)}$ or in situations where a player develops concussive or unusual symptoms, ${ }^{(18)}$ the formulation of an appropriate management plan assumes crucial importance.

Carson et al examined the consistency of advice on concussion among SEM physicians and EPs using a self-reported online questionnaire. ${ }^{(19)}$ Despite the low response rates, most SEM physicians (74\%) were aware of the Sport Concussion Assessment Tool version 2 (SCAT2), ${ }^{(20)}$ and almost all (97\%) SEM physicians knew about concussion guidelines. In contrast, only $12 \%$ of EPs were aware of the SCAT2 assessment tool and over half $(59 \%)$ were unaware of available guidelines for clinical management. ${ }^{(19)}$ 
With the increasing emphasis on physical activity and sports in Singapore, participation in and popularity of collision sports at both the amateur and professional levels have increased in recent years. In keeping with this development, it is imperative that clinicians are aware of the international guidelines, diagnosis, immediate management and disposition of concussed patients. This will hopefully mitigate the long-term sequelae of concussion and result in more favourable outcomes for athletes.

The present study aimed to: (a) establish the clinical exposure of EPs to concussion in EDs; (b) gauge the knowledge of EPs in relation to symptoms of concussion, common presentations and clinical management; and (c) determine if clinical experience and training in concussion management can influence the prior two factors.

\section{METHODS}

A 17-item anonymised Google Forms survey consisting of two parts was formulated (Table I). Section 1 collected demographic information about the respondents, including their clinical grade (e.g. medical officer, registrar, associate consultant, consultant, senior consultant), previous training in concussion, and years of experience at the current place of work. Section 2 focused specifically on the respondent's knowledge of the subject matter, with questions on the definition, common presentations, treatment and management of concussion. All questions had to be completed in order to submit the survey.

The survey was sent via email to EPs from a single ED within a restructured (government) hospital setting in Singapore between August and September 2016. The email contained information regarding the purpose of the study, need for consent to participate, confirmation that no identifiable information would be recorded should the survey be completed and a weblink to the Google form. Following the initial communication, two follow-up emails were sent to EPs on the mailing list to improve response rates.

The following inclusion criteria were applied: (a) all respondents should be classified as permanent staff; (b) all respondents should be currently working in the ED; and (c) respondents could be of any clinical grade. Temporary or shortterm contracted EPs were excluded from the study. The survey was sent to all 65 permanent EPs in the ED. Although previous studies assessing concussion knowledge had achieved a response rate of only $41 \%$, ${ }^{(19)}$ using an online sample size calculator with the confidence level set at $95 \%$ and power at $80 \%$, ${ }^{(21)}$ the minimum number of survey responses required for our study was 52 . To minimise the risk of selection bias, all the EPs were contacted with each email communication, and the same information was provided, including the reasons for the survey, consent, anonymisation and a weblink to the form.

Descriptive statistics were used to analyse the responses, and the frequencies for the questions were calculated. IBM SPSS Statistics version 22.0 (IBM Corp, Armonk, NY, USA) and Fisher's exact test were used to determine if there was any association between clinical grade or training in concussion management and responses to questions examining concussion knowledge. Statistical significance was set at $p<0.05$. The following
Table I. Survey form questions.

\begin{tabular}{|c|c|}
\hline Question & Type \\
\hline \multicolumn{2}{|l|}{ Section 1: Demographics } \\
\hline What is your grade? & $M C Q$ \\
\hline Did you train in Singapore? & Yes/No \\
\hline If not, where? & Free text \\
\hline $\begin{array}{l}\text { How long have you been at your current place of } \\
\text { work? }\end{array}$ & $\mathrm{MCQ}$ \\
\hline $\begin{array}{l}\text { Have you had any training for sports concussion } \\
\text { management? }\end{array}$ & Yes/No \\
\hline \multicolumn{2}{|l|}{ Section 2: Concussion knowledge } \\
\hline How would you define concussion? & Free text \\
\hline How often do you see sports concussion cases? & $M C Q$ \\
\hline $\begin{array}{l}\text { What is the best imaging modality for } \\
\text { concussions? }\end{array}$ & $M C Q$ \\
\hline $\begin{array}{l}\text { Are you aware of internationally recognised } \\
\text { guidelines for sports-related concussion? }\end{array}$ & Yes/No \\
\hline Do you use such a guideline in your department? & Yes/No \\
\hline $\begin{array}{l}\text { Are there different guidelines for adults and } \\
\text { children for sports-related concussion? }\end{array}$ & Yes/No \\
\hline $\begin{array}{l}\text { Do you make onward referrals for sports } \\
\text { concussion? }\end{array}$ & Yes/No \\
\hline If so, to whom? & $M C Q$ \\
\hline $\begin{array}{l}\text { Which symptom of concussion do you think is } \\
\text { the most common? }\end{array}$ & $M C Q$ \\
\hline $\begin{array}{l}\text { If there is no loss of consciousness, do you think } \\
\text { you are able to make a diagnosis of concussion? }\end{array}$ & Yes/No \\
\hline $\begin{array}{l}\text { Do you ever give patients any advice regarding } \\
\text { returning to play? }\end{array}$ & Yes/No \\
\hline $\begin{array}{l}\text { Do non-clinical factors (e.g. medicolegal, players' } \\
\text { and parents' concerns) affect your decision in } \\
\text { allowing a patient to return to play? }\end{array}$ & Yes/No \\
\hline
\end{tabular}

MCQ: multiple-choice question

associations were included in the assessment: (a) clinical grade versus definition of concussion/recognition of common symptoms/appropriate imaging; and (b) clinical experience or previous training (in concussion management) versus definition of concussion/recognition of common symptoms/appropriate imaging.

\section{RESULTS}

Out of 65 EPs, 52 responded to the anonymous online survey over the two-month data collection period, giving a response rate of $80 \%$. Among the 52 respondents, 25 (48.1\%) were medical officers, 7 (13.5\%) were resident physicians, 6 (11.5\%) were registrars, $4(7.7 \%)$ were associate consultants $(0-2$ years after completing specialist training), $4(7.7 \%)$ were consultants (> 2 years after completing specialist training) and 6 (11.5\%) were senior consultants ( $>5$ years after completing specialist training) (Fig. 1).

A majority of the EPs (39/52, 75.0\%) had worked in the hospital for $<5$ years, while $5(9.6 \%)$ had worked there for $5-10$ years and $8(15.4 \%)$ for $>10$ years. Most of the EPs (31/52, $59.6 \%$ ) had trained in Singapore; among the rest, $48 \%$ were trained in Europe, $42 \%$ in another Asian country and $10 \%$ in Australasia. Almost all the EPs (48/52, 92.3\%) had not undergone 


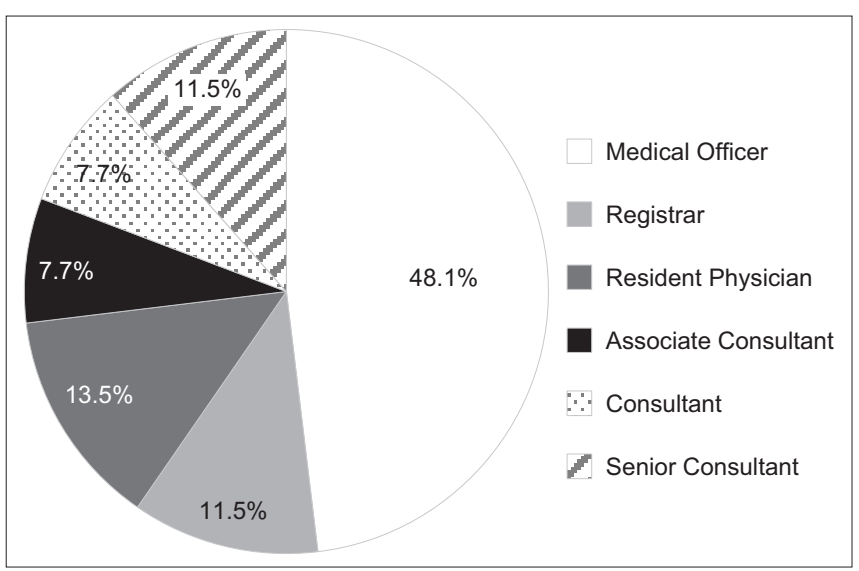

Fig. 1 Pie chart shows the proportion of emergency physicians of each clinical grade who were surveyed.

any formal concussion education during their undergraduate or postgraduate training.

The reported clinical exposure to concussion varied, with $11(21.2 \%)$ of the EPs managing it on a daily basis, $14(26.9 \%)$ seeing patients with concussion at least weekly and 13 (25.0\%) doing so on a monthly basis (Fig. 2). In all, 38 (73.1\%) of the EPs were managing concussion on a regular basis (i.e. at least monthly). A small proportion (4/52, 7.7\%) reported that they had never assessed or treated concussion in a clinical setting (all these responses were provided by medical officers).

In our study, 16 (30.8\%) EPs correctly defined concussion according to the criteria set out in the 2012 consensus statement, ${ }^{(1)}$ but $39(75.0 \%)$ were unaware of existing clinical guidelines for managing concussion. Although the number of EPs who responded correctly $(26 / 52,50.0 \%)$ to the question on choice of imaging modality were comparable with those who did not, only $24(46.2 \%)$ EPs correctly identified the most common symptom of concussion. Most EPs (40/52; 76.9\%) recognised that loss of consciousness was not required for a diagnosis of concussion and $37(71.2 \%)$ EPs indicated that nonclinical factors, such as medicolegal considerations, influenced their decision-making. $39(75.0 \%)$ EPs referred patients with concussion to other specialists from the ED, with a majority of 29 (55.8\%) EPs making referrals to neurosurgery for further opinion (Fig. 3).

There was no significant difference between the different clinical grades of EPs and positive responses for correct definition $(p=0.518)$, imaging modality $(p=0.652)$ and most common symptom $(p=0.325)$ of concussion. Similarly, there was no significant difference between reported prior training in concussion management and positive responses for correct definition ( $p=1.000)$, imaging modality $(p=1.000)$ and most common symptom ( $p=0.590)$ of concussion.

\section{DISCUSSION}

Concussion remains a complex condition, with multiple risk factors identified and complex presentations. ${ }^{(22)}$ Over the past decade, there have been considerable advances in the medical management of this condition and it continues to evolve. ${ }^{(23)}$

To the best of our knowledge, this is the first study assessing the knowledge and management of concussion by EPs in Singapore.
In total, 52 out of 65 EPs contacted for the survey responded, giving a response rate of $80 \%$. A majority of respondents were junior doctors, which reflects the normal hierarchical distribution of most medical teams in the ED. Among the non-responders, the majority were also medical officers, with the exception of one senior consultant.

In our study, patients with concussion were fairly frequently seen at the ED, with most clinicians being exposed to them on an almost monthly basis. If we were to extrapolate this to include non-responders, one would estimate about 780 cases of concussion presenting to the ED annually. However, only 81 cases of concussion were documented over a 12-month period and there was no subdivision for sports concussion. On the other hand, over 849 minor head injuries were documented for the same time period, suggesting that concussions were possibly being miscoded under the heading of minor head injuries. A better classification system for injuries presenting to the ED, with a dedicated injury database, could be the answer; indeed, a dedicated electronic health record in the United States appears to have helped in the management of paediatric concussions. ${ }^{(24)}$

While over $90 \%$ of clinicians reported a lack of concussion training, a key finding was the absence of a significant difference in the correct responses received for the definition, imaging modality and most common symptom of concussion between EPs who had received training on the subject and those who had not. While the nature of the training/education was not determined or explored in our survey, our results question the robustness of the educational process and whether it was of sufficient quality.

As responses to the definition of concussion were sought as free text, the survey challenged individuals to recall what they might have previously learnt rather than simply seeking a bestfit option from a multiple-choice format. As more than $60 \%$ of clinicians incorrectly defined the problem, it was unsurprising that investigations (including magnetic resonance imaging and computed tomography) were proposed, when it is not generally indicated at initial presentation, or that, when conducted, it required specialised reporting. ${ }^{(25,26)}$ Notably, the practice of onward referral to neurosurgery persisted despite surgical intervention not being required for a vast majority of patients with concussion. These results were in keeping with a study from Canada, which found that a gap in understanding influenced clinical decision-making among clinicians providing sport-related concussion management advice. ${ }^{(19)}$

A contributing factor for this limited understanding of concussion may be the rotational nature of postgraduate medical training. Junior doctors often rotate through a number of specialities and thus, every six months, there is a requirement to re-educate a new cohort about the symptoms, signs and management of concussion. In institutions that do not utilise the opportunity to educate clinicians during ED rotations, this might leave an unfilled gap in clinicians' learning. Indeed, with similar responses being received from clinicians of both junior and senior grades in our study, we should question whether education about concussion should be commenced at the undergraduate stage of training rather than being introduced at the postgraduate phase. 


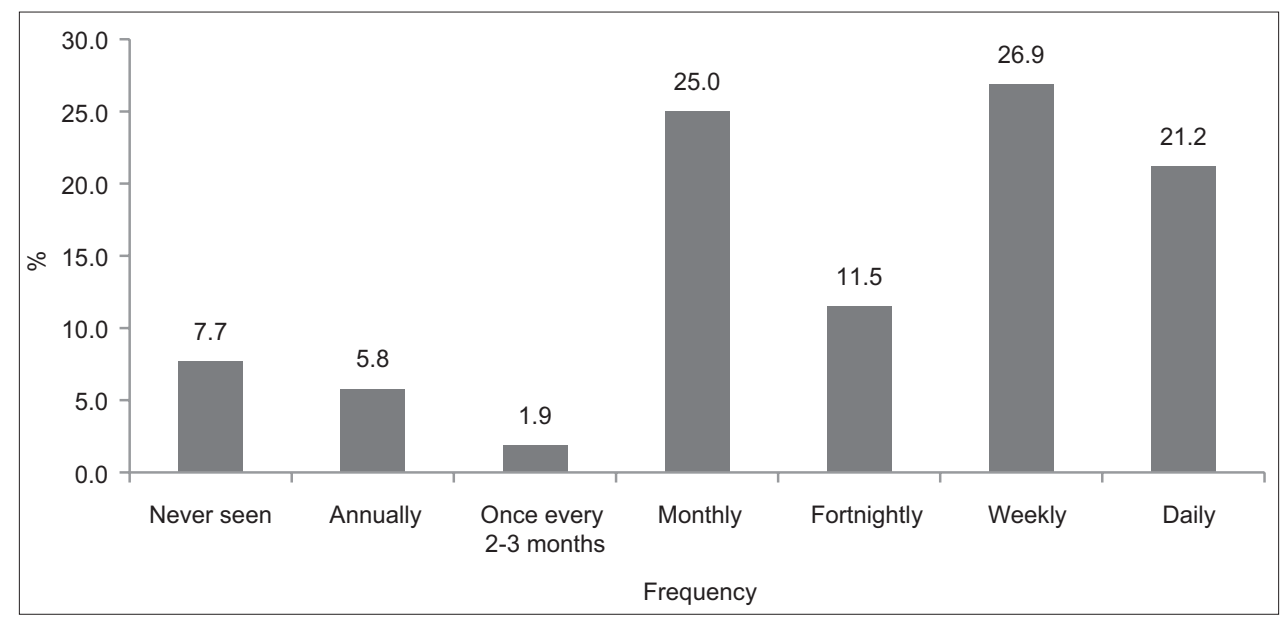

Fig. 2 Graph shows frequency of concussion cases seen by the emergency physicians surveyed.

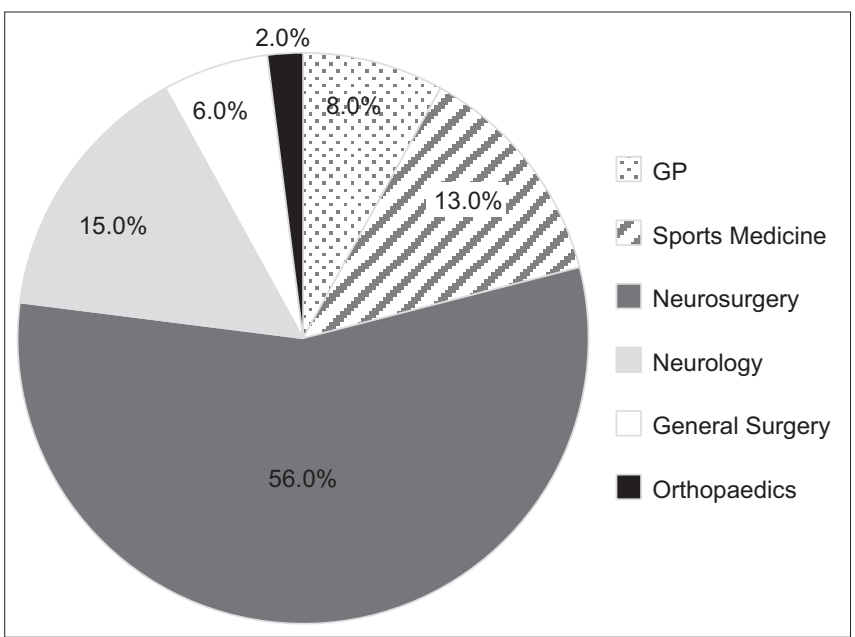

Fig. 3 Pie chart shows pattern of onward referral of patients with concussion by emergency physicians. GP: general practitioner

Several authors have examined the understanding of concussion among undergraduates, with two studies from Canada identifying a lack of knowledge among medical students. ${ }^{(27,28)}$ However, another study from a medical school in the United States found more encouraging results, with $75 \%$ of respondents correctly defining concussion in a multiplechoice question format but significantly fewer being aware of its symptoms and management. ${ }^{(29)}$ In the latter study, although nearly $40 \%$ of respondents had not received teaching on the subject, most were keen to learn more. Efforts to capitalise on this latent interest may improve the acquisition of knowledge among medical students, which can then be reinforced subsequent to their becoming clinicians.

Effective delivery of this education is also important. Echlin et al, who studied an online training system to educate teenagers about the significance of concussion and the need to adhere to treatment, found that it significantly improved understanding and knowledge ${ }^{(9)}$ World Rugby offers a similar course, which is free to access and is commonly used by those working in the sport. A Singapore-based resource should perhaps be made available for undergraduates and clinicians to improve management of this condition, as not everyone would rotate through the ED.
The ED surveyed in this study has patients from a variety of age groups within the local population. Indeed, in the context of paediatric patients, with more vulnerable brains and longer recovery periods, ${ }^{(30)}$ one study found that primary care physicians and EPs did not feel fully equipped to provide suitable care to paediatric patients with concussion. ${ }^{(31)}$ However, another study found that trained paediatricians employed a well-known concussion management guideline and thus provided more standardised care. ${ }^{(32)}$

While a majority of EPs did refer patients for further assessment in our study, what was of concern was the number of specialities to which patients were referred for specialist opinion. Bearing these findings in mind, perhaps it would be more pertinent for EPs to be trained in recognising concussion, performing an initial assessment and understanding when to refer patients with concussion to specialists who are more experienced in managing the condition. Educational initiatives focused on the various stakeholders appear to be a key step in improving concussion management, ${ }^{(33)}$ and especially in the ED setting, guideline-based assessments may help to streamline clinical management of patients with concussion while providing necessary knowledge acquisition. ${ }^{(34)}$

Apart from highlighting a paucity of knowledge vis-à-vis concussion and its management in the ED, our study had a number of limitations. Being a single-centre study, the generalisability of our findings was rather limited. However, the department chosen for study was typical of other EDs in Singapore and is one that receives a significant number of patients from its neighbourhood. Therefore, the frequency of concussions assessed by our EPs, as well as their level of understanding of concussion, is likely to be representative of Singapore EDs at large. Our results were likely impacted by recall bias as well. With the survey being completed retrospectively by physicians at a time of their convenience, the possibility of EPs incorrectly estimating the frequency of concussion in the clinical setting cannot be overlooked. This notwithstanding, recall bias was unlikely to have adversely influenced EPs' responses to questions regarding the definition, symptom recognition, investigation and management of concussion.

Responses to the knowledge questions may have been influenced by the online questionnaire itself. With access to the 
Internet while completing the survey, respondents may have looked up the condition, which would then have directed their answers. While this could not have been prevented given the delivery system chosen for the survey, it could be construed to constitute a positive limitation, i.e. one that highlights a learning need that stimulated physicians to read up on the subject matter.

In conclusion, concussion remains a challenging condition to diagnose and manage in the clinical setting. From the responses gathered, it is clear that EPs play a pivotal role in its management, particularly given the frequency of patients with concussion presenting to the ED. However, it also appears that seniority or clinical experience did not significantly influence the understanding or management of this condition. While there have been considerable steps taken to tackle concussion, including policy changes and rule amendments in the sporting environment, onward management remains a key focus for optimising outcomes for affected patients. It is essential that EPS receive training on managing concussion, but it is perhaps of greater importance that they refer patients onward to physicians who have undergone more specific training and have a better understanding of the 'graduated return to play' process. These could be sports physicians in some centres or any other suitably trained physician. Indeed, a structured referral pathway from the ED, improved classification systems, regular educational sessions, and a focus on both undergraduate medical students and qualified clinicians might be the next steps for improving concussion management.

\section{REFERENCES}

1. McCrory $\mathrm{P}$, Meeuwisse $\mathrm{WH}$, Aubry M, et al. Consensus statement on concussion in sport: the 4th International Conference on Concussion in Sport held in Zurich, November 2012. Br J Sports Med 2013; 47:250-8.

2. Sullivan SJ, Schneiders AG, Cheang CW, et al. 'What's happening?' A content analysis of concussion-related traffic on Twitter. Br J Sports Med 2012; 46:258-63.

3. Sirisena D, Walter J, Probert J. National Football League concussion lawsuit: what it means for other sports and observations from Singapore Rugby. Br J Sports Med 2017; 51:696-7.

4. Heiner JA. Concussions in the National Football League: Jani v. Bert Bell/Pete Rozelle NFL player ret. plan and a legal analysis of the NFL's 2007 Concussion Management Guidelines. Seton Hall J Sports Ent Law 2008; 18:255-96.

5. Calderwood C, Murray AD, Stewart W. Turning people into couch potatoes is not the cure for sports concussion. Br J Sports Med 2016; 50:200-1.

6. Tator $\mathrm{CH}$. Sport concussion education and prevention. J Clin Sport Psychol 2012; 6:293-301.

7. Gianotti $\mathrm{S}$, Hume P. Concussion sideline management intervention for rugby union leads to reduced concussion claims. NeuroRehabilitation 2007; 22:181-9.

8. Broglio SP, Cantu RC, Gioia GA, et al; National Athletic Trainer's Association. National Athletic Trainers' Association position statement: management of sport concussion. J Athl Train 2014; 49:245-65.
9. Echlin PS, Johnson AM, Holmes JD, et al. The Sport Concussion Education Project. A brief report on an educational initiative: from concept to curriculum. J Neurosurg 2014; 121:1331-6.

10. Williams JM, Langdon JL, McMillan JL, Buckley TA. English professional football players concussion knowledge and attitude. J Sport Health Sci 2016; 5:197-204.

11. Shenouda C, Hendrickson P, Davenport K, Barber J, Bell KR. The effects of concussion legislation one year later--what have we learned: a descriptive pilot survey of youth soccer player associates. PM R 2012; 4:427-35.

12. Fraas MR, Burchiel J. A systematic review of education programmes to prevent concussion in rugby union. Eur J Sport Sci 2016; 18:1212-8.

13. Mrazik M, Dennison CR, Brooks BL, et al. A qualitative review of sports concussion education: prime time for evidence-based knowledge translation. Br J Sports Med 2015; 49:1548-53.

14. Fu TS, Jing R, McFaull SR, Cusimano MD. Health and economic burden of traumatic brain injury in the Emergency Department. Can J Neurol Sci 2016; 43:238-47.

15. Padegimas EM, Stepan JG, Stoker GE, Polites GM, Brophy RH. Epidemiology and severity of sports and recreation injuries presenting to a tertiary adult emergency department. Phys Sportsmed 2016; 44:263-8.

16. Bakhos LL, Lockhart GR, Myers R, Linakis JG. Emergency department visits for concussion in young child athletes. Pediatrics 2010; 126:e550-6.

17. Kirkwood G, Parekh N, Ofori-Asenso R, Pollock AM. Concussion in youth rugby union and rugby league: a systematic review. Br J Sports Med 2015; 49:506-10.

18. Rimal D, Thapa SR, Munasinghe N, Errington M. An unusual presentation of a minor head injury sustained during a game of rugby. Emerg Med J 2007; 24:485-6.

19. Carson JD, Rendely A, Garel A, et al. Are Canadian clinicians providing consistent sport-related concussion management advice? Can Fam Phys 2016; 62:494-500.

20. SCAT2. Br J Sports Med 2009; 43:i85-8

21. OpenEpi. Open Source Epidemiologic Statistics for Public Health. Updated 6th April 2013. Available at: http://www.openepi.com/SampleSize/SSPropor. htm. Accessed May 13, 2016

22. Abrahams S, Fie SM, Patricios J, Posthumus M, September AV. Risk factors for sports concussion: an evidence-based systematic review. Br J Sports Med 2014; 48:91-7.

23. Williams VB, Danan IJ. A historical perspective on sports concussion: where we have been and where we are going. Curr Pain Headache Rep 2016; 20:43.

24. Arbogast KB, Curry AE, Haarbauer-Krupa J, et al. Novel use of electronic health records to advance research and management of paediatric concussions. Inj Prev 2016; 22(Suppl 2):A245.

25. Eierud C, Craddock RC, Fletcher S, et al. Neuroimaging after mild traumatic brain injury: review and meta-analysis. Neuroimage Clin 2014; 4:283-94.

26. McAllister TW, Sparling MB, Flashman LA, Saykin AJ. Neuroimaging findings in mild traumatic brain injury. J Clin Exp Neuropsychol 2001; 23:775-91.

27. Boggild $\mathrm{M}$, Tator $\mathrm{CH}$. Concussion knowledge among medical students and neurology/neurosurgery residents. Can J Neurol Sci 2012; 39:361-8.

28. Burke MJ, Chundamala J, Tator $\mathrm{CH}$. Deficiencies in concussion education in Canadian medical schools. Can J Neurol Sci 2014; 39:763-6.

29. Donaworth MA, Grandhi RK, Logan K, Gubanich PJ, Myer GD. Is current medical education adequately preparing future physicians to manage concussion: an initial evaluation. Phys Sportsmed 2016; 44:1-7

30. McCrory P, Collie A, Anderson V, Davis G. Can we manage sport related concussion in children the same as in adults? Br J Sports Med 2004; 38:516-9.

31. Zonfrillo MR, Master CL, Grady MF, et al. Pediatric providers' self-reported knowledge, practices, and attitudes about concussion. Pediatrics 2012; 130:1120-5.

32. Gordon KE, Do MT, Thompson W, McFaull S; Canadian Paediatric Surveillance Program Participants. Concussion management by paediatricians: a national survey of Canadian paediatricians. Brain Inj 2014; 28:311-7.

33. Caron JG, Bloom GA, Falcão WR, Sweet SN. An examination of concussion education programmes: a scoping review methodology. Inj Prev 2015; 21:301-8.

34. Bazarian JJ, McClung J, Cheng YT, Flesher W, Schneider SM. Emergency department management of mild traumatic brain injury in the USA. Emerg Med J 2005; 22:473-7. 